
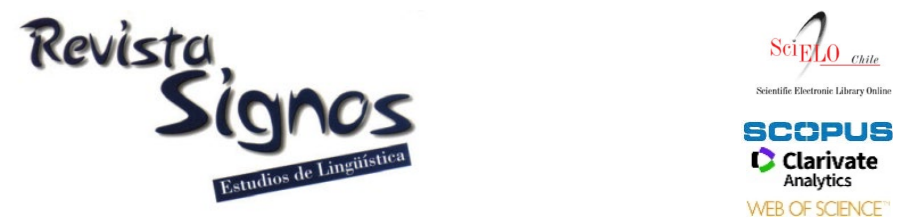

\title{
Special issue: Advances in Spanish for specific purposes in the United States: Connecting the heritage language pedagogy and the Hispanic community*
}

\author{
Sección monográfica: Avances en el español con fines especificos \\ en los Estados Unidos: La conexión entre la enseñanza de \\ lenguas de herencia y la comunidad hispana
}

This special issue 'Advances in Spanish for specific purposes in the United States: Connecting the heritage language pedagogy and the Hispanic community' is offered to the academic community to present the results and perspectives of the work of a selection of scholars in the domain of Revista Signos. Estudios de Lingüistica. With the expansion of Spanish heritage language students in the United States (US) higher education system, institutions, program administrators, and researchers have had to cope with the redesign of their curricula in order to ensure continuity and to strive for the best academic results (Brown \& Thompson, 2018). Therefore, extensive research has been devoted to addressing how best to prepare students by enabling them to gain high-level language and intercultural competencies that will serve them personally and professionally in the international scenario of the twenty-first century. In this development, there have been three key factors that second language (L2) pedagogy experts and language programs directors have focused on separately: community, heritage language (HL) pedagogy, and language for specific purposes (LSP) (Wurr \& Hillebrandt, 2007, inter alia; Abbott \& Lear, 2010; Sánchez-López, 2013; Lafford, 2012; Lafford, Abbott \& Lear, 2014). The eight papers in the present issue of this journal discuss innovative practices and findings in teaching Spanish for specific purposes in a variety of fields, such as academic Spanish, education, intercultural competence, interpretation, and translation.

The first key factor, community-service learning (CSL), arose from the tenets of experiential education and constructivist theories that advocate for learning through 
first-hand discovery (Furco, 2001). The chief characteristic that distinguishes CSL from other types of volunteer or internship endeavors is that students' service experiences are tied to the academic content of an on-campus course or curriculum (Giles, Honnet \& Migliore, 1991). Many US universities promote students' volunteering and CSL. The number of participating universities that use Campus Compact -a national partnership that promotes service to the community and assistance to students to acquire civic dispositions and skills- has grown remarkably, i.e., from 235 institutions in 1991 to more than 1,200 institutions in 2013 (Bowley \& Meerepool, 2013). Research has defined CSL as the "experiential education that engages students in activities that address human and community needs together with structured opportunities" (Jacoby, 1996: 5). Robert Sigmon (1996: 4), one of the pioneers in the field of service-learning, highlighted that: "each participant is server and served, care giver and care acquirer, contributor and contributed to". Although CSL was introduced in the United States in the 1960s, only recently has it been developed for all education levels. In fact, the United States was the second country after Mexico to incorporate it as a component of students' academic curricula (Rubio Serrano \& Escofet Roig, 2018). In the context of the United States, Wurr and Hillebrandt (2007) were pioneers in identifying the intrinsic relationship between Spanish language study and the Hispanic community's needs in this country.

Second, language and literature departments have also worked hard to provide their student population with a meaningful and pragmatic language experience (Brown \& Thompson, 2018). To this end, those individuals who identify ethnically as Hispanic are defined as heritage language learners (HLL) of Spanish, whose degree of proficiency in Spanish and cultural connection to the language differs significantly from that of second language learners (SLL) for linguistic, cognitive, cultural, and social reasons. In Valdés' (2000) words, a heritage language learner is an individual:

"Who is raised in a home where a non-English language is spoken, who speaks or merely understands the heritage language, and who is to some degree bilingual in English and the heritage language" (Valdés, 2000: 1).

The third and final factor, LSP, also represents a key component of the twentyfirst-century Spanish curricula by bridging the gap between what students learn in the classroom and how they use this knowledge outside of the classroom. LSP has been approached from different perspectives, but one of the definitions that best exemplifies the nature of this volume states it as follows:

"Specific purposes teaching refers to a distinctive approach to language education based on identification of the specific language features, discourse practices, and communicative skills of target groups, and on teaching practices that recognize the particular subject matter needs and expertise of learners" (Hyland, 2009: 201). 
Even though these three factors have found to be decisive in the development of Spanish at the postsecondary level in the United States, little evidence exists of their connections jointly. Key questions which have not received full-fledged attention in the previous literature will be addressed in this volume. The present monograph has been organized to precisely showcase some of the work being conducted by scholars within and around these questions. Thus, this volume responds to the growing demand for more comprehensive research that delves further into the impact of the incorporation of the Hispanic community component on Spanish heritage students enrolled in Spanish for specific purposes courses.

This special issue is organized in two parts and each article explores a different scenario of the LSP curricula that opens pathways for incorporating the Hispanic community component into the Spanish HL education. The first part includes a total of five articles that analyze the strengths of these three interdisciplinary fields, and the second part is composed of two empirical studies which reveal the outcomes of the aforementioned connections.

Gregory L. Thompson and Alan V. Brown open the first part in this volume by presenting strategies to effectively teach Spanish for specific purposes to HLLs who develop their linguistic and cultural competences through community service learning. The authors also address some of the challenges faced by connecting Spanish HLLs with local Hispanic community partners with which students will be working. They conclude by providing suggestions on how community-based service and learning experiences can be used to help heritage speakers of Spanish not only see the benefits of courses on language for specific purposes, but also transfer their skills across disciplines to apply their learning in additional areas of study.

In the third article, Diana M. Ruggiero analyzes a specific framework for heritage learner service learning in LSP courses. The author identifies several benefits of service learning for HLLs and considers the implications of their needs in the design of LSP courses including CSL projects. The author concludes that an asset-based approach is key to maximizing CSL benefits for HLLs in LSP courses.

In this line, 'Challenges and opportunities for heritage language learners in interpreting courses in the U.S. context' by Christopher D. Mellinger and Laura Gasca-Jiménez aims to understand the role and profile of HLLs in interpreting courses, and encourages further work in this area by investigating the underexplored relationships among LSP, HL education, and the Hispanic community.

The fifth article, by Angela George and Meghann M. Peace, examines the role of an LSP course (i.e., Spanish for academic purposes) in two university-level contexts (San Antonio, Texas, United States, and Calgary, Alberta, Canada) for HLL education. Students' comments taken from a diverse array of community-based activities show 
that they can gain critical insights into issues of language use through their own research.

The contribution offered by Lourdes Sánchez-López explores an ecological approach to Spanish teaching and learning and CSL for the advanced mixed L2 and HL learner classroom in an LSP course. In this design, both L2 and HL students work as a team in close collaboration with Hispanic community partners to explore and transform the linguistic landscape of their own community. Sánchez-López provides a description of the linguistic project and its preliminary pedagogical implications.

Christine E. Poteau opens the second part of this volume by arguing for attention to four key areas to assist Spanish language teachers for effective intercultural communication: (1) the role of intercultural competence development across disciplines and in CSL programs in the state of New Jersey; (2) interdisciplinary approaches to CSL program development; (3) the connection between Spanish L2 and HL learners for LSP courses; and (4) the empirical examination of the benefits of CSL in Interpretation and Translation courses.

In the next paper, Laura Valentín-Rivera finds through a case study how the involvement in a Spanish translation course embedded in a CSL tasks shapes the professional and multicultural profile of a Spanish HLL. The author also establishes the relationship between the online and computerized visual resources and the way the community-based tasks were completed. Results provide knowledge that could facilitate further understanding of the relevance of service-learning when teaching Spanish to HLLs, particularly in the state of Kansas.

Finally, to close this special issue, Francisco Salgado-Robles and Edwin M. Lamboy present a preliminary effort to integrate and assess the community engagement component of a Spanish for education professionals for HLLs of this language. Twenty-one participants are pre-service 7-12 Spanish teachers at two middle-sized, public postsecondary institutions in the state of New York. Results reveal how Spanish HLLs' professional and linguistic skills are further developed by participating in a pre-service teacher program that included a CSL component. Authors conclude with pedagogical implications for $\mathrm{HL}$ instruction and the implementation of further CSL in LSP and propose directions for future research.

And so, I am pleased to guest-edit this collection of essays for Revista Signos. Estudios de Lingüistica in hopes of not only providing new fresh data to research into the field of Spanish for specific purposes, but also serving to encourage specialists in LSP in the United States to pursue further investigation on the promising issues raised here. The primary purpose of this special monograph is to advance and disseminate the various lines of research undertaken by LSP practitioners and scholars in the United States, but, in doing so, we also hope to contribute to debate around a growing 
field of interest among applied linguists: the liaison between the Hispanic community and HL teaching initiatives.

\title{
Francisco Salgado-Robles
}

\author{
Guest Editor \\ College of Staten Island (CUNY) \\ United States \\ francisco.salgado@csi.cuny.edu
}

\section{REFERENCES}

Abbott, A. \& Lear, D. (2010). The connections goal area in Spanish community service: Learning: Possibilities and limitations. Foreign Language Annals, 43(2), 231-245.

Bowley, E. \& Meerepool, J. (2013). Service-learning in higher education: Trends, research, and resources. Generator, 21(3), 12-16.

Brown, A. V. \& Thompson, G. (2018). The Changing Landscape of Spanish Language Curricula: Designing Higher Education Programs for Diverse Students. Washington, DC: Georgetown University Press.

Furco, A. (2001). Advancing service-learning at research universities. New Directions for Higher Education Series, 114, 67-78.

Giles, D., Honnet, E. P. \& Migliore, S. (1991). Research Agenda for Combining Service and Learning in the 1990s. Arlington, VA: National Society for Experiential Education.

Hyland, K. (2009). Specific purpose programs. In M. Long \& C. Doughty (Eds.), The Handbook of Language Teaching (pp. 201-217). New York, NY: Wiley-Blackwell.

Jacoby, B. (1996). Service-learning in today's higher education. In B. Jacoby (Ed.), Service-Learning in Higher Education: Concepts and Practices (pp. 3-25). San Francisco, CA: Jossey-Bass.

Lafford, B. A. (2012). Languages for specific purposes in the United States in a global context: Commentary on Grosse and Voght (1991) revisited. Modern Language Journal, 96(1), 1-27.

Lafford, B. A., Abbott, A. \& Lear, D. (2014). Spanish in the professions and in the community in the US. Journal of Spanish Language Teaching, 1(2), 171-186.

Rubio Serrano, L. \& Escofet Roig, A. (Eds.). (2018). Aprendizaje Servicio (ApS): Claves para Su Desarrollo en la Universidad. Barcelona, Spain: Octaedro. 
Sánchez-López, L. (2013). Service-learning course design for languages for specific purposes programs. Hispania, 96(2), 383-396.

Sigmon, R. (1996). Journey to Service Learning: Experiences from Independent Liberal Arts Colleges and Universities. Washington, DC: Council of Independent Colleges.

Valdés, G. (2000). Introduction. In L. Sandstedt (Ed.), Spanish for Native Speakers. AATSP Professional Development Series Handbook for Teachers K-16, Vol. 1 (pp. 1 20). New York, NY: Harcourt College.

Wurr A. J. \& Hellebrandt, J. (Eds.) (2007). Learning the Language of Global Citizenship. Service-Learning in Applied Linguistics. Bolton, MA: Anker Publishing Co.

\section{*ACKNOWLEDGEMENTS}

I would like to extent my sincere gratitude to the Revista Signos. Estudios de Lingüistica editorial board -and special thanks to Professor Giovanni Parodi Sweis- for offering me the opportunity to guest edit this Special Issue and for providing US scholars in the field of Spanish for specific purposes to present their research. 